\title{
Do stepping-stone jobs exist? Early career paths in the medical profession
}

\author{
Gerard J. van den Berg* \\ Anders Holm ${ }^{\dagger}$ \\ Jan C. van Ours
}

May 28, 1999

\begin{abstract}
In the Netherlands, students who want to become a medical specialist have to enrol in a training program which is in limited supply. During the search for a position as trainee (or "junior medical specialist"), they may accept a temporary job as a medical assistant. We use a micro data set to investigate whether such work experience increases the probability of becoming junior medical specialist. To deal with selectivity, we simultaneously model the transitions from unemployment to trainee, from unemployment to medical assistant, from medical assistant to trainee and from medical assistant to unemployment. We find that a job as medical assistant helps to become a medical specialist.
\end{abstract}

Keywords: job search, multivariate duration models, hazard rate, education, university, treatment effect.

JEL codes: J64, C41, I21.

*Department of Economics, Free University Amsterdam, De Boelelaan 1105,

NL-1081 HV Amsterdam, The Netherlands, Tinbergen Institute, CEPR, and CREST.

${ }^{\dagger}$ Institute of Local Government Studies, Denmark, Nyropsgade 37, DK-1602 Copenhagen V, Denmark.

${ }^{\ddagger}$ Department of Economics, Tilburg University, P.O. Box 90153, NL-5000 LE Tilburg, The Netherlands, CentER for Economic Research and CEPR. 


\section{Introduction}

Since the late 1970s, the econometric analysis of duration variables has become widespread. In the case of unemployment durations, the instantaneous probability of a transition from unemployment to employment is estimated as a function of individual characteristics as well as the elapsed duration itself (see Lancaster, 1990, Devine and Kiefer, 1991, and Van den Berg, 1999, for surveys). Some recent studies focus on the effects of training and other labor market programs. To estimate such an effect, one has to deal with the possibility that enrolment into the program is selective. In the case of nonexperimental data, a solution to this problem is to model both the process by which unemployed enter the program and the process by which they enter employment (see Gritz, 1993, Bonnal, Fougère and Sérandon, 1997, and Abbring, Van den Berg and Van Ours, 1997, for examples).

This paper analyzes particular aspects of the medical education system in the Netherlands, using techniques similar to those in the literature on the effect of training on unemployment duration. The medical education system consists of two successive stages, and, as we shall see below, we focus on the duration between these two stages. The first stage is an extended undergraduate program. Upon completion of this, the individual obtains a degree comparable to a Master's degree. The official title of this degree is basic doctor. A basic doctor who decides to leave the educational system is only allowed to work in a limited range of medical jobs. For example, he is not allowed to work as a physician or as a surgeon. He is however allowed to work as a medical assistant: in such jobs, the individual assists medical specialists, but he does not receive any deliberate training or further education. Work experience as a medical assistant does not result in any qualification or degree. However, as we shall see below, it may facilitate the inflow into the second stage of the medical educational system.

The second stage of the system concerns the education to become surgeon, gynecologist, physician (family doctor), etc. This education is provided in trainee positions in which the individual is supervised by medical specialists for a number of years. We refer to an individual in such a position as a junior medical specialist. ${ }^{1}$ Formally, these positions are temporary jobs. The

\footnotetext{
${ }^{1}$ The literal translations of the Dutch terms used to denote medical assistants and junior medical specialists are: "assistant in medical science not in education" and "assistant in medical science in education", respectively (the corresponding acronyms are AGNIO and
} 
individuals perform regular work and they receive a salary. The number of these positions is limited by the government and by communities of existing medical specialists, and the demand usually exceeds the supply by far. In order to become a junior medical specialist, one generally has to apply for a position, and the application procedure resembles that for standard job applications. For sake of convenience, we refer to the institutions that decide on the applications as the employers. After completion of the second stage, the individual is a medical specialist.

We are interested in the determinants of the rate at which individuals become a junior medical specialist, or, equivalently, the duration of search for a position as junior medical specialist. In particular, we examine whether work experience as a medical assistant increases the individual transition rate to junior medical specialist jobs. At first sight it may seem unlikely that there exists any work experience at all that is valuable as a preparation of junior medical specialist jobs, given that junior medical specialists acquire expert knowledge that enables them to decide on matters of life and death on a regular basis, whereas basic doctors do not. However, working as a medical specialist involves many other skills, including diagnostic testing and social skills, and these may be learned to some extent in medical assistant jobs. Thus, medical assistant jobs may allow the individual to acquire some additional human capital.

There are at least two other reasons for why an employer may prefer to hire workers who have worked in medical assistant jobs. First, having had such a job may be informative on the ability and interests of the individual. The employer of the medical assistant job decided that the individual was qualified for that job, and, by having accepted the job, the individual signals that he is interested in a medical career. The employers of the junior medical specialist jobs may then use medical assistant jobs as a screening or signalling device. This may sort individuals with work experience into junior medical specialist jobs (see Weiss, 1995, for a recent overview of the underlying theory of sorting.) Yet another explanation for an effect of work experience is that the latter enlarges the social network of the individual within the medical world, and this may make it easier for an employer to estimate the quality of the individual as a junior medical specialist.

If work experience has a positive effect, then it is interesting to examine

AGIO). These terms were adopted in the 1980s because of their resemblance to the term "assistant in education" (acronym AIO) which is generally used to denote $\mathrm{PhD}$ students. 
whether the size of the effect depends on the amount of work experience. If work experience as a medical assistant increases human capital or enlarges the relevant social network then the effect should increase with the amount of experience. If the presence of any work experience acts as a signalling device then it is less obvious that the effect depends on the amount of experience. Employers may also use the duration of a medical assistant job and the length of time since graduation as a basic doctor as screening devices. In the former case, a job with a long duration signals satisfaction of the firm at which the individual works, so the expected effect of the duration of the medical assistant job is positive, and this may explain any positive duration dependence of the transition rate from medical assistant to junior medical specialist. In the latter case, individuals with a high elapsed duration since graduation as a basic doctor may become stigmatized, and this decreases their inflow rate into junior medical specialist jobs. This is basically the standard argument for negative duration dependence of the transition rate from unemployment to employment. If the model does not contain the elapsed duration since graduation as a basic doctor as an explanatory variable for the transition rate from medical assistant to junior medical specialist then this shows up as negative duration dependence of this transition rate.

The chances to become a junior medical specialist may be related to the year in which the student became basic doctor, e.g. because the size of the inflowing cohort varies over the years or because the number of junior medical specialist jobs varies. The chances may also depend on the university at which he graduated. Finally, personal characteristics of the student, like age, gender, and duration of undergraduate study, may be important. All these characteristics may also interact with the size of the effect of having a medical assistant job on the chances to become a junior medical specialist. For example, the effect of having a medical assistant job may be smaller for students from a particular university if the curriculum of that university includes a lot of work experience during the education. The data do not enable an assessment of the effect of wages on the transitions, but this is not a serious omission as there is almost no variation in wages across medical assistant jobs and across junior medical specialist jobs.

Our data are from a 1990 survey in which individuals who became basic doctor in 1984, 1986, and 1988, were asked about their labor market history, including any transitions into and out of medical assistant jobs and junior medical specialist jobs. We use these data to estimate a multi-state multi- 
spell duration model. We distinguish between the states of unemployment (which includes having a job outside of the medical sector), having a medical assistant job, and having a junior medical specialist position. The transition rates of importance are modelled as functions of observed and unobserved explanatory variables. Note that allowing for variation of observed and unobserved explanatory variables is necessary in order to correct for a non-random inflow into medical assistant jobs. If individuals for whom it is easy to become junior medical specialist are also over-represented among medical assistants then a casual observer may conclude that there is a positive causal effect even if in reality there is none.

As noted above, our framework resembles the model framework used in some recent non-experimental studies on treatment effects for unemployed workers. To date, there is not yet much experience with the empirical analysis of treatment effects on duration variables, and our analysis contributes to this recent literature (see Van den Berg, 1999, for a survey). Note that there is a crucial difference in terminology between the treatment effect literature and the present paper, as we consider the effect of work experience for individuals who actually aim at getting training (albeit in a job that goes along with the training). Our study thus shows how to estimate a "treatment effect" of work experience on the inflow into an advanced study program, using data on durations spent in different states and transitions between these states. The model, which is basically a mixture of semi-Markov processes, allows for different "treatment effects" for different individuals.

One particular advantage of our data is that they do not suffer from initial conditions problems. This enables consistent estimation of multi-state duration models under relatively weak assumptions (compare e.g. the complications encountered by Ham and LaLonde, 1996, and Van den Berg, Lindeboom and Ridder, 1994). Further, for some respondents the data contain multiple observations per spell type. This greatly facilitates the identification and estimation of the joint distribution of the unobserved heterogeneity variables entering the transition rates (see e.g. Honoré, 1993, and Van den Berg, 1999).

The plan of the paper is as follows. Section 2 provides some additional information on the Dutch medical education system. Section 3 contains a brief theoretical discussion of the search behavior of an individual in the specific labor market we consider. Section 4 presents the data, and Section 5 discusses the econometric model specification we use in the empirical analysis. 
This accounts for the possible endogeneity of the medical assistant job as an intermediate stage between undergraduate education and a junior medical specialist. Section 6 contains the estimation results. Section 7 concludes.

\section{Flows in the medical education system}

As noted in the introduction, the Dutch medical education system consists of two successive stages, and the inflow into the second stage is restricted by the rationing of available slots. Basic doctors (i.e., those who have finished the first stage) may go from the first to the second stage by way of other labor market states, like unemployment, or having a temporary job outside the medical sector. Many basic doctors, however, work for a while as a medical assistant and in the meantime search further for a junior medical assistant job. Figure 1 shows three typical routes from the moment one becomes a basic doctor to the moment one becomes a junior medical specialist. First, a basic doctor may work as medical assistant until a job as junior medical specialist is found. Second, a basic doctor may immediately start as a junior medical specialist, without an intermediate medical assistant job spell. Third, a basic doctor can move from unemployment to a medical assistant job, subsequently drop back into unemployment, and then finally enter a junior medical specialist job.

About $90-95 \%$ of the basic doctors find a job within one year after finishing the first stage. So, at first sight, the labor market position of the basic doctors may seem to be not so bad. Indeed, the unemployment rate among all doctors (including basic doctors and medical specialists) was about $6 \%$ in the second half of the 1980s. However, the vast majority of the basic doctors aim at becoming a medical specialist (recall that this term here includes physicians), and the mere fact that a basic doctor is employed is not informative on whether he is a (junior) medical specialist. During the second half of the 1980s, the annual outflow from the first stage of medical education was about 1500-1600. This number exceeds number of available positions in the second stage of the education system. The annual inflow into medical specialist jobs fluctuated around 1100 during that period (it decreased from about 1200 in 1985 to about 1000 in 1990), and the average waiting time for the latter type of jobs was quite long. The number of medical assistant jobs increased from about 500 in 1985 to about 800 in 1990.

There are basically three types of junior medical specialist jobs, each of 
them corresponding to a particular type of medical specialist job. The first type concerns physicians, with an annual inflow of 400 into the junior medical specialist program. The second type concerns medical specialists proper (surgeons, gynecologists, psychiatrists etc.; there are about 30 different specializations), with a total annual inflow of about 500. The third type concerns "socio-medical doctors", which mainly work for insurance companies, with an annual inflow of about 200.

\section{Search for jobs in the medical sector}

Like in unemployment duration models, the individual transition rates are the focal points in our model. According to job search theory, the transition rate from unemployment to employment is the product of the rate at which the individual receives job offers and the probability that such an offer is acceptable to the individual (see e.g. Mortensen, 1986). The rate at which job offers arrive depends on the intensity by which individuals and employers search, on the matching technology, and on the probability that an employer offers a job to the individual given that a contact is made. The latter probability depends on the characteristics of the individual in comparison to the job requirements. Individuals use a reservation wage strategy: if the wage offer is equal to or larger than a specific reservation wage the offer is accepted, whereas if the wage offer is lower than the reservation wage the offer is rejected and the individual keeps on searching. The probability that a job offer is acceptable equals the probability that the wage offer exceeds the reservation wage. More generally, if a job is characterized not just by its initial wage, then the individual compares the present utility value of the job to the present value of searching further.

Now let us examine the search environment of the basic doctors searching for junior medical specialist jobs and medical assistant jobs. The corresponding labor market is actually quite transparent. First, there is a small flow of vacancies that are being created, and their existence is probably common knowledge upon creation. Second, there is no non-degenerate wage offer distribution, since the starting wage and the subsequent wages in both types of positions are determined by nation-wide rules. It is therefore likely that every job offer is acceptable for every searching individual. This is of course conditional on the choice of the type of medical specialization. Although wage paths within a particular type of medical specialization may not be very dif- 
ferent, there are large differences in the long-run wage paths across different types of medical specialization.

In our analysis, we are particularly interested in three transition rates: from unemployment to junior medical specialist, from unemployment to medical assistant, and from medical assistant to junior medical specialist. From the above we infer that these transition rates are mostly determined by the search behavior and selection strategy of the employer. This means that if there are differences in the hazard rate across basic doctors, then these reflect employers' behavior and aggregate labor market conditions (like the number of agents active on both sides of the market).

\section{The data}

The data were collected by the union of Dutch basic doctors (see Commissie Werkgelegenheid LBB, 1992, for details) in March 1990. From three cohorts of basic doctors $(1984,1986$, and 1988), random samples of 500 each were drawn from the register of medical practitioners of the National Health Inspection, These were subsequently surveyed by mail. The response rate is about $75 \%$. The net sample of 1088 observations is representative with respect to gender ( $75 \%$ men, $25 \%$ women) and undergraduate university (there are eight universities with a medical school: the two Amsterdam universities, Groningen, Leiden, Maastricht, Nijmegen, Rotterdam, and Utrecht). The data record personal and household characteristics, the respondent's education and labor market history (including transition dates), and subjective responses about preferences.

Table 1 provides some summary statistics of the duration data. Like in the previous section, we distinguish between three labor market states: unemployment, medical assistant and junior medical specialist. The first two states are transitory, whereas the third is an absorbing state. This yields four different possible transitions: from unemployment to medical assistant, from unemployment to junior medical specialist, from medical assistant to junior medical specialist, and from medical assistant to unemployment. The state of unemployment is defined as a residual state that covers every situation but medical assistant jobs and junior medical specialist jobs. Most importantly, it includes jobs outside the medical sector. As we shall see below, it is computationally unfeasible to distinguish between different sub-states of this residual state in the model. Also, recall that our primary interest is in the 
transitions into junior medical specialist jobs. Jobs outside the medical sector are most likely of minor relevance for the selection strategy of the employers of junior medical specialist jobs.

On average, the data contain more than two spells per individual. The average duration for completed spells from unemployment into junior medical specialist jobs is shorter than the average duration of spells from medical assistant jobs to junior medical specialist jobs. However, note that the fraction of medical assistant job spells leading to a transition into a junior medical specialist job is much higher than the fraction of unemployment spells leading to such a transition. It may be interesting to note that, among the respondents in a junior medical specialist job, only about $20 \%$ claimed that they obtained the position because of the medical assistant job they had had before.

Figure 2 depicts the estimated Kaplan-Meier hazard functions for the four transition rates (the time unit is a month, and the function values are blown up by a factor 100; note that these blown-up function values are approximately equal to monthly exit percentages). The transition rate from unemployment to medical assistant (Figure 2a) sharply declines over the duration of unemployment. Many individuals move to a medical assistant job shortly after they become basic doctor. The small peak at 16-18 months can be explained by the fact that military service is counted as unemployment. Some individuals may have fulfilled their military service right after the moment they become basic doctor, in which case they are only able to accept assistant positions after about 16 months. $^{2}$

Figure $2 \mathrm{~b}$ displays the transition rate from unemployment to junior medical specialist jobs. This rate is more or less constant, with the exception of a sharp peak at 22 months. The remaining peaks are due to the fact that the number of individuals in the risk set is very small. Although the peak at 22 months occurs somewhat later than the peak in Figure 2a, it may also be due to military service.

The transition rate from medical assistant jobs to junior medical special-

\footnotetext{
${ }^{2}$ It can be argued that it is not correct to count military service as unemployment: in general it is not possible to leave military service for a job before the service time is completed, so the corresponding individuals have an unemployment exit rate of zero. To investigate to what extent the results are sensitive to this, we re-estimated the model under the alternative assumption that military service does not add to the unemployment duration. It turns out that there is no substantial effect on the conclusions. It should be noted that military service was only compulsory for a subset of male basic doctors.
} 
ist jobs is slightly increasing in the elapsed duration of the job, with peaks around 12 and 24 months (see Figure 2c). These peaks may reflect the fact that medical assistant jobs often have contracts with a fixed duration. This is an interesting feature of the medical assistant jobs. Even if a job as medical assistant is beneficial for one's chances of getting an offer of a job as junior medical specialist, the observed transition rate into the latter jobs may be low for some medical assistants who just started in their job, because of this "locking in" property. By comparing Figures $2 \mathrm{~b}$ and $2 \mathrm{c}$ we observe that the transition rate from medical assistant to junior medical specialist is higher than the rate from unemployment to junior medical specialist, for most durations. This suggests that being a medical assistant does help to become junior medical specialist. However, this comparison does not take account of the selectivity discussed in Section 1.

The transition rate from medical assistant jobs back into unemployment (Figure 2d) has peaks at the same points as the transition rate in Figure 2c, with additional peaks at 3 and 6 months. This probably also reflects the fixed duration of the contracts if some medical assistant jobs. Over all, except for the peaks, the transition rate in Figure $2 \mathrm{~d}$ seems constant. We now turn to a formal statistical analysis of the data.

\section{The model specification}

\subsection{The transition rates}

Let the indices 1, 2, and 3 denote the states of "unemployment", "medical assistant", and "junior medical specialist". The transition rate from state $i$ to state $j$ is denoted by $\theta_{i j}$. Consider a spell in state $i$. The survivor function for survival in state $i$ can be expressed as

$$
S_{i}(t)=\exp \left(-\sum_{j=1, j \neq i}^{j=3} \int_{0}^{t} \theta_{i j}(s) d s\right), \quad i=1,2
$$

We define the censoring indicator $d_{i j}$ to equal 1 if a transition into state $j$ is made, with $d_{i j}=0$ otherwise. Suppose we observe $m_{i}$ spells in state $i$, for some individual. We extend the definition of $d_{i j}$ by introducing a third index $k$ denoting the spell at hand. The log likelihood contribution for this individual can then be expressed as 


$$
\sum_{i=1}^{2} \sum_{k=1}^{m_{i}} \log S_{i}\left(t_{k}\right)+\sum_{j=1, j \neq i}^{j=3} d_{i j k} \log \theta_{i j}\left(t_{k}\right)
$$

Note that if $d_{i j k}=0$ for all permissible combinations of $i$ and $j$ then the corresponding duration is right-censored. The only unknowns in this model are the $\theta_{i j}$ functions. Note that the likelihood is separable in the $\theta_{i j}$, so that they can be estimated separately (see e.g. Lancaster, 1990). Below we extend this model framework by introducing observed and unobserved explanatory variables.

First, we allow the individual transition rates to depend on observed explanatory variables, as follows,

$$
\theta_{i j}(t \mid x)=\lambda_{i j}(t) \exp \left(\beta_{i j}^{\prime} x_{i j}\right)
$$

where $\lambda_{i j}$ is a baseline hazard, $\beta_{i j}$ is a vector of state and exit specific parameters, and $x_{i j}$ contains some (possibly) state and exit specific regressors. Note that this defines a proportional hazard model framework for each $\theta_{i j}$, and the likelihood function is still separable.

We include the following explanatory variables in $x$, for each transition rate. First, we have two dummy variables representing cohorts that became basic doctor in 1986 ("Graduate 86 ") and 1988 ("Graduate 88 "), so that the third cohort of 1984 is the reference group. Second, we include age and gender. The variable "Age" measures the age at the start of the spell, so it is constant within spells but not across spells for a given individual. Third, we include the duration of the undergraduate study. Finally, in a preliminary analysis we investigated whether the university at which the undergraduate study was carried out is an important explanatory variable in the model. With the exception of Utrecht, this was never the case. Therefore, we use one additional dummy variable for Utrecht. Table 2 provides some sample statistics for the explanatory variables.

The inclusion of unobserved heterogeneity allows for measurement errors in the dependent variable as well as omitted unobserved covariates; see Lancaster (1990). Here we propose a mixed proportional hazard model for each transition rate, by introducing multiplicative random effects $v_{i j}$ that are state and exit specific,

$$
\theta_{i j}\left(t \mid x, v_{i j}\right)=\lambda_{i j}(t) \exp \left(\beta_{i j} x_{i j}\right) v_{i j}
$$


For a given individual, the values of $v_{i j}$ are assumed to be identical across different spells in state $i$.The survivor function for survival in state $i$, given $x$ and given $v \equiv\left(v_{12}, v_{13}, v_{21}, v_{23}\right)$, can be expressed as

$$
S_{i}(t \mid x, v)=\exp \left(-\sum_{j=1, j \neq i}^{j=3} \int_{0}^{t} \theta_{i j}\left(s \mid x, v_{i j}\right) d s\right), \quad i=1,2
$$

To deal with selective inflow into the states "medical assistant" and "junior medical specialist", we allow the $v_{i j}$ variables to be related for a given individual. For example, the observed transition rate from "medical assistant" to "junior medical specialist" may be higher than the observed rate from "unemployment" to "junior medical specialist" just because individuals for which it is easy to become junior medical specialist tend to self-select into medical assistant jobs (for example, $v_{12}$ is positively related to $v_{13}$ which in turn equals $\left.v_{23}\right)$.

Since $v$ is unobserved, it must be integrated out of the conditional likelihood. The marginal individual likelihood contribution (given $x$ ) equals

$$
\log \int_{v} \prod_{i=1}^{2} \prod_{k=1}^{m_{i}} S_{i}\left(t_{k}\right) \prod_{j=1, j \neq i}^{j=3}\left[\theta_{i j}\left(t_{k}\right)\right]^{d_{i j k}} d F(v)
$$

where $F$ is the cumulative distribution function of $v$ in the inflow into the population of basic doctors. In general, the likelihood function is not separable anymore in the parameters of the different transition rates.

\subsection{Functional forms}

For the duration dependence functions $\lambda_{i j}(t)$ and the multivariate unobserved heterogeneity distribution $F(v)$ we take the most flexible specifications used in the literature to date. We take $\lambda_{i j}(t)$ to have piecewise constant specifications. Let the positive time axis be subdivided into a finite number of intervals numbered $1,2, \ldots$ from the origin onwards. The piecewise constant specification can then be written as

$$
\lambda_{i j}(t)=\sum_{\tau=1,2, \ldots} \lambda_{i j \tau} I_{\tau}(t)
$$

where $t$ denotes the elapsed duration, the subscript $\tau$ refers to consecutive duration intervals, the functions $I_{\tau}(t)$ are time-varying dummy variables that 
are equal to 1 iff $t$ is in interval $\tau$, and $\lambda_{i j \tau}$ are the parameters to be estimated. Note that with an increasing number of time intervals any duration dependence pattern can be approximated arbitrarily closely. By now it is well known that duration dependence specifications with only one parameter (like a Weibull specification) are overly restrictive (see e.g. Lancaster, 1990). In the empirical analysis we adopt the following intervals $\tau$ : $0-1,1-2,2-4$, $4-12$, and $12+$, where the month is the time unit.

We take the distribution of the unobserved heterogeneity terms $v$ to be discrete with a finite number of mass points, and we take both the locations of the mass points and the associated probabilities to be unknown parameters. Let $p_{n}$ with $n=1,2, \ldots, N$ denote probabilities that add to 1 , and let $v_{i j n}$ denote a realization of the random variable $v_{i j}$. We assume that

$$
\operatorname{Pr}\left(v_{i j}=v_{i j n}\right)=p_{n} \quad \text { for all } i j \in\{12,13,21,23\}
$$

and $\quad v_{i j}=v_{i j n} \quad \Leftrightarrow \quad v_{i^{*} j^{*}}=v_{i^{*} j^{*} n} \quad$ for all $i j, i^{*} j^{*} \in\{12,13,21,23\}$

This family of distributions is a special case of the general multivariate discrete distribution for $\left(v_{12}, v_{13}, v_{21}, v_{23}\right)$. The latter has $N$ possible realizations of each $v_{i j}$, while every combination of realizations of $v_{i j}$ and $v_{i^{*} j^{*}}$ is allowed, so that the vector $v$ has $N^{4}$ possible realizations. This amounts to $N^{4}+4 N-1$ unknown parameters, which is unfeasible even for $N=2$. In contrast, our specification has only $5 N-1$ unknown parameters. It restricts the general multivariate distribution by imposing a deterministic relation between the elements of $\left(v_{12}, v_{13}, v_{21}, v_{23}\right)$. Note that the latter relation is not imposed to be monotone. In the empirical analysis, we report standard errors for the estimates conditional on the value of $N$.

For given $N$, the total number of unknown parameters equals the sum of: (a) the number of elements of $\beta_{i j}$ (six) times the number of $i j$-combinations (four), (b) the number of parameters $\lambda_{i j \tau}$ (five) times the number of $i j$ combinations (four), and (c) $5 N-1$ parameters of the specification of $F(v)$, minus four normalizations. This sum equals $5 N+39$. Clearly, if we would divide the state of unemployment into a number of sub-states then the number of parameters would become too large for estimation.

In the above model, the effect of a medical assistant job on the individual transition rate into a junior medical specialist job follows from a comparison of $\theta_{23}\left(t \mid x, v_{23}\right)$ and $\theta_{13}\left(t \mid x, v_{13}\right)$. If the baseline hazards $\lambda_{i j}(t)$ are constant then these transition rates are constant over time, and their ratio defines the 
change in the rate into junior medical specialist jobs that is due to having a medical assistant job, for an individual with a given $x$ and $v$. Non-constant baseline hazards take account of the way in which this effect changes over the durations of the medical assistant job and unemployment, respectively. The fact that we allow for $\beta_{13} \neq \beta_{23}$ and that we allow for $v_{13} / v_{23}$ to be different across individuals means that we allow the individual effect of a medical assistant job to differ between individuals. The average effect is obtained by averaging the individual effect over $x, v$. As noted above, the extent to which $v_{12}$ is related to $v_{13}$ and $v_{23}$ determines the extent to which selectivity affects the relation in the raw data between having a medical assistant job or not and the rate of entering a junior medical specialist job.

The model of this section implies that (properties of) the distribution of the observed durations are quite complicated non-linear functions of the parameters. Some caution on identification therefore seems appropriate. By Heckman and Honoré (1989), the parameters of a flexible competing risks model with mixed proportional hazards are nonparametrically identified under weak conditions. Our model implies competing risks specifications for the exits out of unemployment as well as for the exits out of medical assistant jobs. The distribution of $v$ in the inflow into medical assistant jobs is determined by the distribution of $v$ in the outflow out of unemployment. Note that in both cases we observe more than in a competing risks model, as the observation window only ends upon a transition into the state of junior medical specialist jobs (or because of right-censoring). Moreover, we may observe multiple spells in the states of unemployment and medical assistant jobs. A formal proof of nonparametric model identification along the lines of Heckman and Honoré (1989) is beyond the scope of this paper.

To investigate the sensitivity of the results with respect to parametric assumptions, we estimated a number of alternative versions of the model. First, we estimated the model version with the restrictions $\beta_{23}=\beta_{13}$ and $v_{23}=v_{13}$. These are restrictions across the exit rates into a junior medical specialist position. Given these restrictions, the individual effect of a medical assistant job is captured by the difference between the levels of the baseline hazards $\lambda_{13}$ and $\lambda_{23}$, so this individual effect is now the same for every individual. The restrictions make the model more similar to the model framework of Heckman and Honoré (1989), because the unobserved heterogeneity term that affects the transition rate into junior medical specialist jobs is now the same across the states of origin. The estimates of this model version are significantly dif- 
ferent from those for the model without these restrictions. However they lead qualitatively and also quantitatively to the same conclusions on the effect of being in a medical assistant position.

One could argue that the $\theta_{i j}$ transition rates should be allowed to depend on the elapsed time since the moment the individual became basic doctor, or on whether the individual has ever been medical assistant, or on other lagged endogenous variables. However, this demands even more of the data in terms of (nonparametric) identification. We experimented with the estimation of such general specifications, but it turned out to be impossible to obtain convergence of the estimation procedure to reasonable parameter values. We also experimented with alternative specifications that do not nest the model of this section (e.g. by allowing the transition rate into junior medical specialist jobs to depend on whether the individual has ever been medical assistant, but not on any other feature of the current or past labor market state). It turns out that the estimate of the effect of having a medical assistant job on the rate into junior medical specialist jobs is robust with respect to this.

\section{Estimation results}

The parameter estimates are presented in Tables 3a-3c. Table 3a shows the parameter estimates of the covariate effects, Table $3 \mathrm{~b}$ shows the estimates of the baseline hazards, and Table $3 \mathrm{c}$ shows the estimates of the parameters of the distribution of unobserved heterogeneity.

In Table 3a we show estimates for the main model as well as for a simpler model that does not account for unobserved heterogeneity. From the table we infer that the model allowing for correlated unobserved heterogeneity in the exit rates yields a considerably higher likelihood than the model without heterogeneity. Hence inference on the effects of the covariates and having an assistant position should be based on the model allowing for heterogeneity. Note that some of the estimated covariate effects differ substantially between the two model specifications. ${ }^{3}$

\footnotetext{
${ }^{3}$ We also estimated a model with uncorrelated unobserved heterogeneity in all four transition rates. For the exit rates out of unemployment, this model yields quite similar estimates as the model allowing for correlated unobserved heterogeneity, whereas for the exit rates out of medical assistant jobs there is no evidence of heterogeneity in this model. At first sight this may be interpreted as evidence that allowing for unobserved heterogeneity per se is more important than allowing for dependence of the unobserved
} 
We first examine the transition rate from unemployment into medical assistant jobs. As we shall see below, such a position increases the chances of obtaining a junior medical specialist job. None of the cohort effects (the "Graduate" parameters) is significant. "Age" is very significant and negative, so this type of transition is more likely to be made by younger basic doctors. Finally, we note that there is a significant gender but no significant university ("Utrecht") effect. Conditional on other characteristics, females are more likely to make a transition into a medical assistant job.

Next we look at the transition from unemployment to junior medical specialist jobs. Here we note that "Graduate 86 " and "Graduate 88 " are significant and negative. This indicates that junior medical specialist jobs are harder to obtain for unemployed in the latter cohorts than for unemployed in the first cohort. This is probably because of the reduction in the number of junior medical specialist jobs in the second half of the 1980s, but it could also be caused by crowding out of unemployed basic doctors by medical assistants. More and more basic doctors are searching for junior medical specialist positions from medical assistant jobs, leaving less chances for unemployed basic doctors, if employers prefer the former over the latter. All other coefficients are insignificant in this transition.

The transition rate from medical assistant jobs to junior medical specialist jobs is also lower for later cohorts (the coefficients of both "Graduate 8 " and "Graduate 88 " are negative and significant). This cohort difference is, however, of smaller size than the corresponding difference among the unemployed basic doctors, so medical assistants suffer less from the increased shortage of junior medical specialist jobs than otherwise comparable unemployed basic doctors. Of the other coefficients only those of age and gender are significant. Conditional on the other characteristics older medical assistants have a smaller transition rate to junior medical specialist, while for females this transition rate is larger.

For the transition from medical assistant to unemployment, apart from a small cohort effect, only the variable "Studytime" is significant at a 10 $\%$ significance level. It is negative, indicating that individuals with a high undergraduate study time are less likely to leave medical assistant jobs for unemployment.

heterogeneity terms. However, such an interpretation is invalid, as the models with correlated and uncorrelated heterogeneity are not nested and their likelihood values cannot be compared. 
All in all, the estimation results in Table 3a indicate that cohort, age and gender are important determinants of the process by which basic doctors find a job as junior medical specialist. Individuals in later cohorts find it more difficult to become junior medical specialist, since both the direct transition rate from unemployment and the indirect transition rate via a job as a medical assistant are smaller than they are for earlier cohorts.

We proceed to analyze the level and slope of the baseline hazards and the size of the mean "treatment effect" of having a medical assistant job on the transition rate into junior medical specialist jobs. The estimated baseline hazard coefficients are given in Table $3 \mathrm{~b}$ (the table lists the estimates of $\left.\log \lambda_{i j \tau}\right)$. Figure 3 depicts the transition rates of interest, as functions of the elapsed duration, for a person with average sample statistics and average estimated $v{ }^{4}$ The figure shows a dramatic difference between the over-all levels of two transition rates, indicating the difference in the possibilities of finding a junior medical specialist job from an assistant position vis-àvis from unemployment. We return to the magnitude of this difference after having discussed the baseline hazard estimates. The transition rate from a medical assistant job into junior medical specialist jobs is initially virtually zero. This probably reflects some "locking in effect" from minimum contract durations of medical assistant jobs. Also note that this transition rate declines after 12 months of search. There is a similar sharp decline in the transition rate from unemployment to junior medical specialist jobs. Nevertheless, the fact that the rate from a medical assistant job to junior medical specialist jobs diminishes over the duration of the medical assistant job indicates that accumulation of human capital is not a major reason for employers to prefer individuals who are medical assistant. For the same reason, work experience as medical assistant is not expected to have a major effect on the size of the social network that may be used to obtain a junior medical specialist job. Apparently, the fact that the individual has a medical assistant job acts primarily as a (positive) signal for employers. The fact that the transition rate decreases may be due to a stigma effect of a high length of time since the moment the individual became basic doctor, as hypothesized in section 1 . In addition, the individual may regard a job as a junior medical specialist as an investment, and the shorter the pay-back time of this investment, the lower the willingness to make it. Note that this may also explain the estimated

\footnotetext{
${ }^{4}$ If background variables are set to other values then the levels of the transition rates change.
} 
"Age" effects above.

Table 4 displays the size of the mean effect of having a medical assistant job from another angle. It gives the simulated fraction of individuals who have obtained a junior medical specialist job, from a medical assistant job and from unemployment, respectively, as functions of the elapsed durations since inflow into the corresponding state. These calculations are based on average values of the background characteristics. The results in this table confirm that initially the transition rate from medical assistant jobs to junior medical specialist jobs is low. However, after 12 months the proportion of medical assistants who have entered a junior medical specialist job is twice as large as the proportion of unemployed who have entered such a job.

Table $3 \mathrm{c}$ gives the estimates for the unobserved heterogeneity distribution (it lists the estimates of $\log v_{i j n}$ and $p_{n}$ ). This distribution has three points of support, so one could imagine three groups of homogeneous basic doctors. A small group of about $2 \%$ has very unfavorable prospects in the medical education system. They have a relatively low exit rate from unemployment both to medical assistant jobs and to junior medical specialist jobs. Moreover, once an individual in this group has a medical assistant job, he has a relatively low transition rate to a junior medical specialist position and a relatively high transition rate back to unemployment. A group of about $18 \%$ has the best prospects for becoming junior medical specialist. They have relatively high transition rates from unemployment to medical assistant jobs and junior medical specialist jobs. Moreover, their transition rate to a junior medical specialist position is relatively high and their transition rate back to unemployment is relatively low. The remaining group of $80 \%$ has an intermediate position in terms of the magnitude of all the transition rates.

\section{Conclusions}

The main empirical result of this study is that it is beneficial for individuals to accept a job as a medical assistant in order to become junior medical specialist. Having a job as medical assistant substantially increases the transition rate to junior medical specialist jobs. The results are corrected for possible selectivity effects by taking account of unobserved heterogeneity in the individual transition rates. Without this correction we would have estimated a smaller "treatment" effect.

From the estimated duration dependence pattern of the transition rate 
from medical assistant jobs to junior medical specialist jobs we infer that the former type of job does not provide much human capital that could serve as input for the latter type of job. The treatment effect can therefore not be attributed to accumulation of human capital. Similarly, being a medical assistant does not have a major effect on the size of the social network that may be used to obtain a junior medical specialist job. Apparently, the fact that the individual has a medical assistant job acts primarily as a positive signal for employers. It indicates that candidates are suitable for and/or interested in a medical career.

The results indicate that there are strong cohort effects. For individuals in later cohorts it is more difficult to find a job as junior medical specialist. Both the direct transition rate from unemployment and the indirect transition rate via a job as a medical assistant are smaller than they are for earlier cohorts. This may be due to crowding out of unemployed basic doctors by medical assistants, which may be enhanced by the reduction in the number of junior medical specialist jobs in the second half of the 1980s. 


\section{References}

Abbring, J.H., G.J. van den Berg and J.C. van Ours, 1997, The effect of unemployment insurance sanctions on the transition rate from unemployment to employment, Tinbergen Institute Working Paper, Amsterdam/Rotterdam.

Bonnal, L., D. Fougère And A. SÉrandon, 1997, Evaluating the impact of French employment policies on individual labour market histories, Review of Economic Studies, 64, 683-713.

Commissie Werkgelegenheid LBB, 1992, Basisarts: dokteren aan je toekomst ("Basic doctor: mastering your future"), Report, Vrije Universiteit Amsterdam.

Devine, T.J. And N.M. Kiefer, 1991, Empirical Labor Economics: The Search Approach, Oxford University Press, Oxford.

Gritz, R.M., 1993, The impact of training on the frequency and duration of employment, Journal of Econometrics, 57, 21-51.

HAM, J.C. AND R.L. LALONDE, 1996, The effect of sample selection and initial conditions in duration models: evidence from experimental data on training, Econometrica, 64, 175-205.

Heckman, J.J. And B.E. HonorÉ, 1989, The identifiability of the competing risk model, Biometrika, 76, 325-330.

Honoré, B.E., 1993, Identification results for duration models with multiple spells, Review of Economic Studies, 60, 241-246.

LAnCASter, T., 1990, The econometric analysis of transition data, Cambridge University Press, Cambridge.

Mortensen, D.T., 1986, Job search and labor market analysis, in O. Ashenfelter and R. Layard (eds.), Handbook of Labor Economics, Volume II, North-Holland, Amsterdam.

Van den Berg, G.J., M. Lindeboom and G. Ridder, 1994, Attrition in longitudinal panel data, and the empirical analysis of dynamic labor market behaviour, Journal of Applied Econometrics, 9, 421-435. 
VAN DEN Berg, G.J., 1999, Duration models: specification, identification, and multiple durations, in J.J. Heckman and E. Leamer (eds.), Handbook of Econometrics, Volume V, North-Holland, Amsterdam.

Weiss, A., 1995, Human capital vs. signalling explanations of wages, Journal of Economic Perspectives, 9, 133-154. 
Table 1. Summary statistics on durations.

\begin{tabular}{|l|l|}
\hline \# of persons & 1088 \\
\hline \# of spells & 1869 \\
\hline av. duration of $1-2$ transitions & 6.0 \\
\hline av. duration of $1-3$ transitions & 13.7 \\
\hline av. duration of $1-$ ? transitions & 13.2 \\
\hline \# of $1-2$ transitions & 682 \\
\hline \# of $1-3$ transitions & 128 \\
\hline \# of $1-$ ? transitions & 1228 \\
\hline av. duration of $2-3$ transitions & 17.4 \\
\hline av. duration of $2-1$ transitions & 13.6 \\
\hline av. duration of $2-?$ transitions & 18.6 \\
\hline \# of $2-3$ transitions & 199 \\
\hline \# of $2-1$ transitions & 123 \\
\hline \# of $2-?$ transitions & 641 \\
\hline \# of censored spells & 737 \\
\hline
\end{tabular}

Note: states 1, 2, and 3 are unemployment, medical assistant, and junior medical specialist, respectively. A question mark denotes right-censoring.

Table 2. Summary statistics on explanatory variables.

\begin{tabular}{|l|l|l|}
\hline Variable & Description & Average \\
\hline Graduate $_{84}$ & 1 if graduated in 1984, 0 otherwise. & 0.34 \\
\hline Graduate $_{86}$ & 1 if graduated in 1986, 0 otherwise. & 0.32 \\
\hline Graduate $_{88}$ & 1 if graduated in 1988, 0 otherwise. & 0.34 \\
\hline Age & age in months/120 at the outset of the spell. & $2.85^{*}$ \\
\hline Studytime & duration (months/120) spent at university before basic doctor. & 0.81 \\
\hline Gender & 1 if female, 0 otherwise. & 0.34 \\
\hline Utrecht & 1 if graduated at University of Utrecht, 0 otherwise. & 0.15 \\
\hline
\end{tabular}

* The value of this variable thus varies across spells. 
Table 3a. Estimation results for covariate effects.

\begin{tabular}{|c|c|c|c|c|}
\hline & \multicolumn{2}{|c|}{ No heterogeneity } & \multicolumn{2}{|c|}{ With heterogeneity } \\
\hline Variable & estimate & std. error & estimate & std. error \\
\hline & \multicolumn{4}{|c|}{ Unemployment to medical assistant } \\
\hline Graduate $_{86}$ & 0.313 & 0.404 & 0.245 & 0.484 \\
\hline Graduate $_{88}$ & 0.464 & $0.201^{* *}$ & 0.395 & 0.231 \\
\hline Studytime & -0.017 & 0.052 & -0.019 & 0.046 \\
\hline Age & -0.301 & $0.073^{* *}$ & -0.300 & $0.075^{* *}$ \\
\hline Utrecht & 0.220 & 0.434 & 0.197 & 0.256 \\
\hline \multirow[t]{2}{*}{ Gender } & 0.233 & $0.079^{* *}$ & 0.250 & $0.096^{*}$ \\
\hline & \multicolumn{4}{|c|}{ Unemployment to junior medical specialist } \\
\hline Graduate $_{86}$ & -0.580 & $0.228^{* *}$ & -0.525 & $0.266^{* *}$ \\
\hline Graduate $_{88}$ & -1.160 & $0.421^{* *}$ & -1.034 & $0.524^{* *}$ \\
\hline Studytime & -0.050 & 0.083 & -0.044 & 0.087 \\
\hline Age & 0.055 & 0.064 & 0.055 & 0.076 \\
\hline Utrecht & -0.214 & $0.124^{*}$ & 0.188 & 0.145 \\
\hline \multirow[t]{2}{*}{ Gender } & -0.123 & 0.267 & 0.075 & 0.231 \\
\hline & \multicolumn{4}{|c|}{ Medical assistant to junior medical specialist } \\
\hline Graduate $_{86}$ & -0.236 & $0.119^{* *}$ & -0.247 & $0.146^{*}$ \\
\hline Graduate $_{88}$ & -0.961 & $0.411^{* *}$ & -0.926 & $0.432^{* *}$ \\
\hline Studytime & 0.007 & 0.041 & 0.007 & 0.042 \\
\hline Age & -0.737 & $0.252^{* *}$ & -0.750 & $0.281^{* *}$ \\
\hline Utrecht & 0.093 & $0.041^{* *}$ & 0.058 & 0.041 \\
\hline \multirow[t]{2}{*}{ Gender } & 0.236 & $0.122^{*}$ & 0.244 & $0.142^{*}$ \\
\hline & \multicolumn{4}{|c|}{ Medical assistant to unemployment } \\
\hline Graduate $_{86}$ & -0.071 & 0.240 & -0.239 & 0.225 \\
\hline Graduate $_{88}$ & 0.027 & 0.041 & -0.190 & $0.085^{* *}$ \\
\hline Studytime & -0.021 & $0.011^{* *}$ & -0.014 & $0.008^{*}$ \\
\hline Age & -0.151 & 0.116 & 0.146 & 0.124 \\
\hline Utrecht & -0.146 & 0.215 & -0.156 & 0.256 \\
\hline Gender & -0.421 & $0.232^{*}$ & -0.502 & 0.276 \\
\hline $\log \mathrm{L}$ & \multicolumn{2}{|l|}{5055.1} & \multicolumn{2}{|l|}{5023.3} \\
\hline
\end{tabular}

Note: * indicates two-sided significance at a $10 \%$ level.

** indicates two-sided significance at a $5 \%$ level. 
Table 3b. Estimation results for baseline hazard.

\begin{tabular}{|c|c|c|c|c|}
\hline & \multicolumn{2}{|c|}{ No heterogeneity } & \multicolumn{2}{|c|}{ With heterogeneity } \\
\hline & Estimate & std. error & Estimate & std. error \\
\hline & \multicolumn{4}{|c|}{ Unemployment to medical assistant } \\
\hline 0-1 month & 0.078 & 0.058 & 0.240 & 0.075 \\
\hline $1-2$ months & -1.677 & 0.114 & -1.533 & 0.123 \\
\hline $2-4$ months & -2.335 & 0.167 & -2.172 & 0.172 \\
\hline $4-12$ months & -2.977 & 0.139 & -2.813 & 0.143 \\
\hline \multirow{2}{*}{$12+$ months } & -4.417 & 0.316 & -4.267 & 0.319 \\
\hline & \multicolumn{4}{|c|}{ Unemployment to junior medical specialist } \\
\hline $0-1$ month & -3.212 & 0.267 & -3.123 & 0.416 \\
\hline $1-2$ months & -3.264 & 0.378 & -3.103 & 0.455 \\
\hline $2-4$ months & -3.709 & 0.378 & -3.567 & 0.457 \\
\hline$\overline{4-12 \text { months }}$ & -3.574 & 0.267 & -3.373 & 0.327 \\
\hline \multirow[t]{2}{*}{$12+$ months } & -4.606 & 0.278 & -4.111 & 0.261 \\
\hline & \multicolumn{4}{|c|}{ Medical assistant to junior medical specialist } \\
\hline $0-1$ month & -5.274 & 0.448 & -5.267 & 0.464 \\
\hline $1-2$ months & -4.612 & 0.265 & -4.236 & 0.188 \\
\hline $2-4$ months & -3.743 & 0.180 & -3.591 & 0.216 \\
\hline$\overline{4-12 \text { months }}$ & -2.922 & 0.177 & -2.651 & 0.154 \\
\hline \multirow[t]{2}{*}{$12-$ months } & -3.772 & 0.213 & -3.469 & 0.230 \\
\hline & \multicolumn{4}{|c|}{ Medical assistant to unemployment } \\
\hline $0-1$ month & -0.838 & 0.228 & -0.863 & 0.288 \\
\hline $1-2$ months & -3.730 & 0.120 & -4.090 & 0.305 \\
\hline $2-4$ months & -3.415 & 0.218 & -3.879 & 0.266 \\
\hline 4-12 months & -3.490 & 0.267 & -3.879 & 0.324 \\
\hline $12+$ months & -4.630 & 0.277 & -5.081 & 0.288 \\
\hline
\end{tabular}

Note: Estimates shown are for $\log \lambda_{i j \tau}$. 
Table 3c. Estimation results for unobserved heterogeneity distribution.

\begin{tabular}{|c|c|c|}
\hline Mass point $n$ & Estimate $\log v_{i j n}$ & std. error \\
\hline & Unemployment to medical assistant & \\
\hline 1. & 0 & - \\
\hline 2. & -0.084 & 0.066 \\
\hline \multirow[t]{2}{*}{3.} & -1.080 & $0.404^{* *}$ \\
\hline & Unemployment to junior medical specialist & \\
\hline 1. & 0 & \\
\hline 2. & -0.244 & 3.520 \\
\hline \multirow[t]{2}{*}{3.} & -0.973 & $0.245^{* *}$ \\
\hline & Medical assistant to junior medical specialist & \\
\hline 1. & 0 & - \\
\hline 2. & -0.340 & 0.426 \\
\hline \multirow[t]{2}{*}{3.} & -1.855 & $0.525^{* *}$ \\
\hline & Medical assistant to unemployment & \\
\hline 1. & 0 & - \\
\hline 2. & 0.659 & $0.130^{* *}$ \\
\hline 3. & 1.914 & $0.642^{* *}$ \\
\hline \multicolumn{3}{|l|}{ Probability $p_{n}$} \\
\hline$p_{1}$ & 0.183 & - \\
\hline$p_{2}$ & 0.798 & $0.401^{*}$ \\
\hline$p_{3}$ & 0.019 & $0.005^{* *}$ \\
\hline
\end{tabular}


Table 4. Simulated duration distributions for an average individual.

\begin{tabular}{|l|l|}
\hline \multicolumn{2}{|l|}{ Unemployment to medical assistant } \\
\hline Proportion of spells ended after: \\
\hline 1 month & $2.0 \%$ \\
\hline 2 months & $3.9 \%$ \\
\hline 4 months & $6.4 \%$ \\
\hline 12 months & $17.3 \%$ \\
\hline Medical assistant to junior medical specialist \\
\hline Proportion of spells ended after: \\
\hline 1 month & $0.3 \%$ \\
\hline 2 months & $1.3 \%$ \\
\hline 4 months & $4.9 \%$ \\
\hline 12 months & $35.1 \%$ \\
\hline
\end{tabular}

Note: The simulated probabilities are calculated for an average person in the data set. 
Figure 1. Typical job histories.

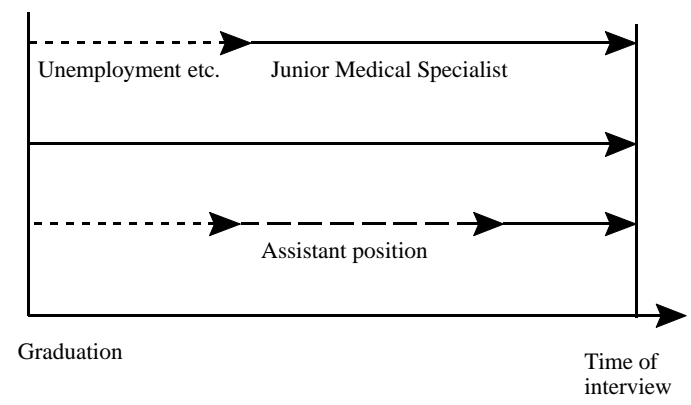



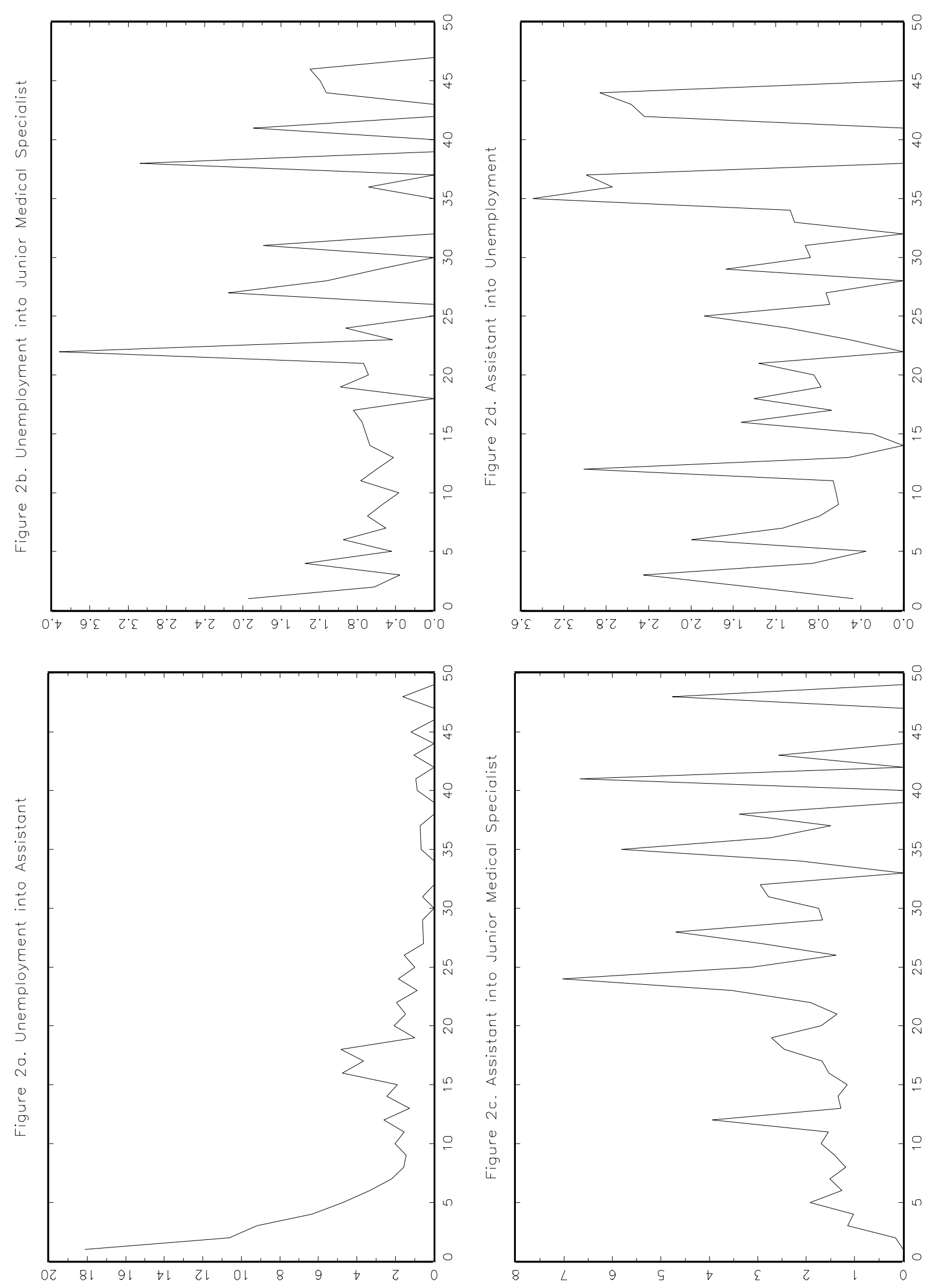


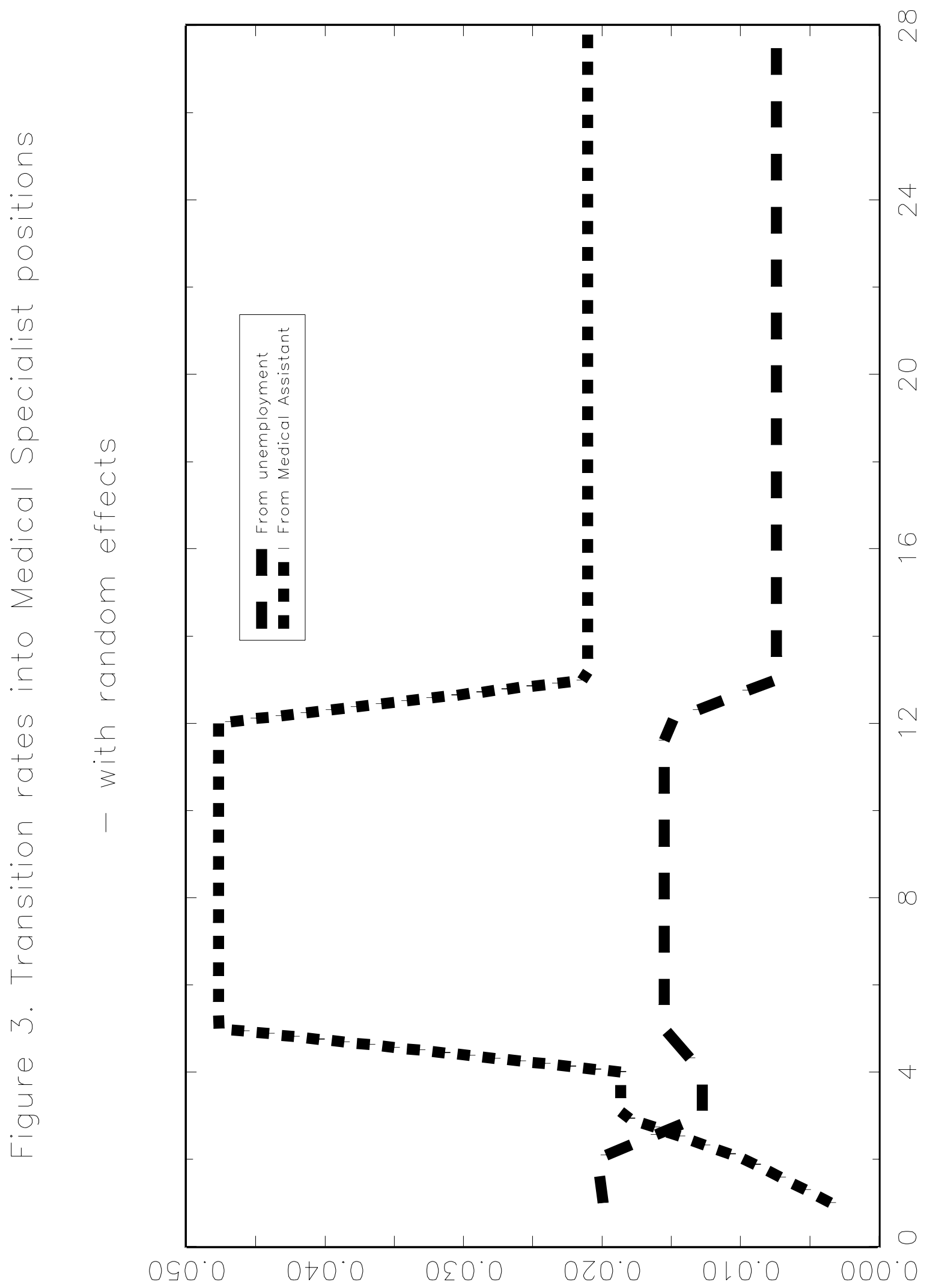

